\title{
Methodology to obtain accurate sea surface temperature from locally received NOAA-14 data in the Canary-Azores-Gibraltar area*
}

\author{
F. EUGENIO ${ }^{1}$, J. MARCELLO ${ }^{1}$, A. HERNÁNDEZ-GUERRA² and E. ROVARIS ${ }^{1}$ \\ ${ }^{1}$ Signal and Communications Department, Universidad de Las Palmas de Gran Canaria, Campus Universitario de Tafira, \\ 35017 Las Palmas de Gran Canaria, Canary Islands, Spain. \\ ${ }^{2}$ Physics Department, Universidad de Las Palmas de Gran Canaria, Campus Universitario de Tafira, \\ 35017 Las Palmas de Gran Canaria, Canary Islands, Spain.
}

\begin{abstract}
SUMMARY: A methodology to obtain the sea surface temperature (SST) in the Canary-Azores-Gibraltar area has been developed. The final accuracy of the AVHRR-based SST retrievals depends both on the accuracy of the measured radiance and the accuracy of the SST retrieval algorithm that converts the measured radiance into sea surface temperature. The procedure made in this framework consists of: (i) a radiance-based non-linearity correction method; (ii) an automatic procedure for the geometric correction, achieving accuracy to the order of the pixel; (iii) an improved algorithm for cloud detection, based on the method of the multiband thresholds; (iv) a new split-window function (SWF) to perform atmospheric correction in CANIGO area. This task has been accomplished by using the matchup data set of AVHRR brightness temperature (channel 4 and 5) and in situ SST data. The matchups were carefully screened from the HRPT scenes of all seasons in 19961998. The temporal and spatial coincidences are within 30 minutes and one pixel resolution, respectively. Coefficients of that algorithm are estimated from regression analysis using 60 co-located in situ and satellite measurements (matchups). Error analysis has shown that SST can theoretically be retrieved to within $0.38^{\circ} \mathrm{C}$ RMS.
\end{abstract}

Key words: sea surface temperature, automatic georeferencing, cloud detection, split window function.

\section{INTRODUCTION}

The sea surface temperature (SST) is an important geophysical parameter essential for quantitative studies of the Earth's atmosphere and oceans. The SST imagery remotely sensed by the Advanced Very High Resolution Radiometer (AVHRR) aboard the NOAA satellite series has been conveniently used in various fields, for example, oceanography, meteorology, fishery, etc. The need for high accuracy in the measurement of sea surface temperature from space was recognised in the early stages of planning

\footnotetext{
*Received September 20, 1999. Accepted August 8, 2000.
}

the World Climate Research Program. Absolute SST accuracy better than $1^{\circ} \mathrm{C}$ is necessary in the study of thermal structures of the sea surface (fronts, isotherms, etc.). With the objective to obtain accurate and automatic temperature maps, a methodology has been developed, that is currently operational in our Remote Sensing Center, including some improvements in the commonly used procedure. These procedures applied to the images from the AVHRR sensor aboard NOAA-14 consist of:

(i) A procedure for AVHRR Infrared (IR) channels calibration using non-linear correcting functions based on those described by Steyn-Ross et al. (1992) and Walton et al. (1998). 
(ii) An improved algorithm for cloud detection based on the method of the multiband thresholds adapted to the CANIGO zone after experimental checking.

(iii) A new split-window function (SWF) to perform atmospheric and emissivity correction in CANIGO area. This has been accomplished by using the matchup data set of AVHRR brightness temperature (channel 4 and 5) and in situ SST data. Coefficients are estimated from regression analysis using 60 co-located in situ and satellite measurements (matchups) and examining the formal dependencies of the variables $T_{11}$ and $T_{12}$, where $T_{11}$ and $T_{12}$ are the radiative temperatures at 11 and $12 \mu \mathrm{m}$ respectively, restricting in-situ measurements to be within about $50^{\circ}$ of the satellite zenith angle.

(iv) An automatic procedure for geometric correction based on a satellite orbital model and a similarity detection algorithm. This procedure uses the automatic identification of coastal features in a digitised coastline map and in the georeferenced image, achieving accuracies to the order of the pixel.

In the next section the theoretical base and a practical application of the procedure have been detailed.

\section{RADIOMETRIC CALIBRATION}

The final accuracy of the AVHRR-based SST retrievals depends both on the accuracy of the measured radiances and the accuracy of the SST retrieval algorithm that converts the measured radiances to sea surface temperature. Thus, it is of great importance that the algorithms that involve infrared measurements get precise values for the radiance. This fact requires a well-defined and consistent calibration procedure, understood as the radiometer output digital values (or count) relative to the actual radiance of the observed scene.

In principle, if the radiometer was perfectly stable, any necessary calibrations could be carried out on ground prior to the launch, obtaining a precise relation between the counts and the radiance. However, because the characteristics of the on-board sensors and electronics may drift with time and environmental changes, a dynamic calibration procedure is required.

The AVHRR IR channels calibration on flight is performed by the monitoring of the radiometer output when it views two targets whose radiance values are known or can be computed: cold space as a zero- radiance reference and an internal calibration blackbody target (ICT) located in the instrument base plate and whose temperature is measured with a four platinium-resistance thermometers (PRTs). These two measurements are used to define a continuously updated linear mapping between count and radiance.

For the NOAA-14 AVHRR sensor, a procedure based on the ones described by Steyn-Ross et al. (1992) and Walton et al. (1998) is used. This procedure corrects the instrumental effects of the AVHRR thermal infrared channels centered at $10.8 \mu \mathrm{m}$ (channel 4) and $12 \mu \mathrm{m}$ (channel 5), whose Hg-CdTe detectors exhibit slight but well-defined non-linearities in their response to incoming radiation. It assignes a non-zero radiance to the cold space view response as proved by Walton et al. (1998).

That radiance is converted to brightness temperature, that is the magnitude of interest, using the inverse Planck function with the appropriate central wavelength numbers that are provided by NESDIS.

\section{AUTOMATIC IMAGE GEOREFERENCING}

The characteristic of the satellite scanning, which covers a $2800 \mathrm{~km}$ wide swath, the spacecraft's speed, altitude and attitude, and the Earth's curvature and rotation, produce significant distortions in the images. It is necessary for image referencing to identify the geographic co-ordinates corresponding to an image pixel (direct referencing) or to locate a pixel corresponding to given geographic co-ordinates (inverse referencing).

A good overview of existing methods for geometric correction of satellite data is given in Krasnopolsky and Breaker (1994) and Rosborough et al. (1994). In the references several models of varying complexity can be found (Ho and Asem, 1986; Bachmann and Bendix, 1992; Moreno and Melia, 1993; Illera et al., 1996). In general the procedure for the georeferencing of NOAA-AVHRR images is based on the combination of an orbital model and ground control points (GCPs).

The objective is to combine the advantages of both methods to obtain a procedure fully automatic and operational which allows the georeferencing of NOAA-AVHRR images with high accuracy and without operator intervention.

The orbital model assumes a circular orbit (Ho and Asem, 1986) and the nominal Kepplerian elements, as well as the time of the first scanned line, the longitude of the ascending node and the equator 
crossing hour. These parameters can be obtained, automatically, from the NOAA-Level 1B data set header and from the weekly archive of the equator crossing file, respectively. In order to correct the errors caused by these simplifications, by a non-zero value for the spacecraft's roll, pitch and yaw and by failures in the satellite's internal clock, a similarity detection algorithm is used.

\section{Systematic errors in the Orbital Model}

The problem of georeferencing consists of finding the relation between the co-ordinates in the image (line, column) and the geographic co-ordinates (lat, lon). This will allow us to geographically locate any pixel in the image (direct reference), or to identify the corresponding image co-ordinates on an AVHRR image, given a set of geographic co-ordinates (inverse reference):

$$
\begin{aligned}
& \text { Line }=F(\text { lat }, \text { lon }) \\
& \text { Col }=G(\text { lat }, \text { lon })
\end{aligned}
$$

This is calculated by mean of the orbital model following the procedure described by Ho and Asem (1986) (inverse referencing). The basic relations for the orbit, the scanner and the Earth are similar to the ones described by Ho and Asem (1986). However, unlike this model that adjusts satellite height $(h)$ and inclination $(i)$ by means of a GCP and the Bachmann and Bendix (1992) and Illera et al.(1996) models, that calculate the longitude of the ascending node $\left(\lambda_{E}\right)$ and the time difference between the equator crossing and the scanned line $\left(t_{E}\right)$ using one or several GCPs, we introduce nominal values $\left(i, h_{s}, \lambda_{E}, t_{E}\right)$.

The use of nominal values, especially the satellite's height and inclination, longitude of the ascending node and the equator crossing hour, as well as the simplifications used considering a circular orbit model around a spherical Earth brings us to the unavoidable errors when the obtained image is superimposed on a digitised coastline.

In order to carry out an analysis of the possible errors, we measure on the coastline and calculate, by means of the orbital model, the co-ordinates of a group of control points, which are used as a test. Results obtained using exclusively the orbital model to correct the NOAA 14-AVHRR image corresponding to 5 of June 1998, with a size of 1400 columns by 1032 rows are shown in Figure 1 .

Figure 1(a) shows that the error in the nadir is around 1 pixel instead of zero as a result of the trans-
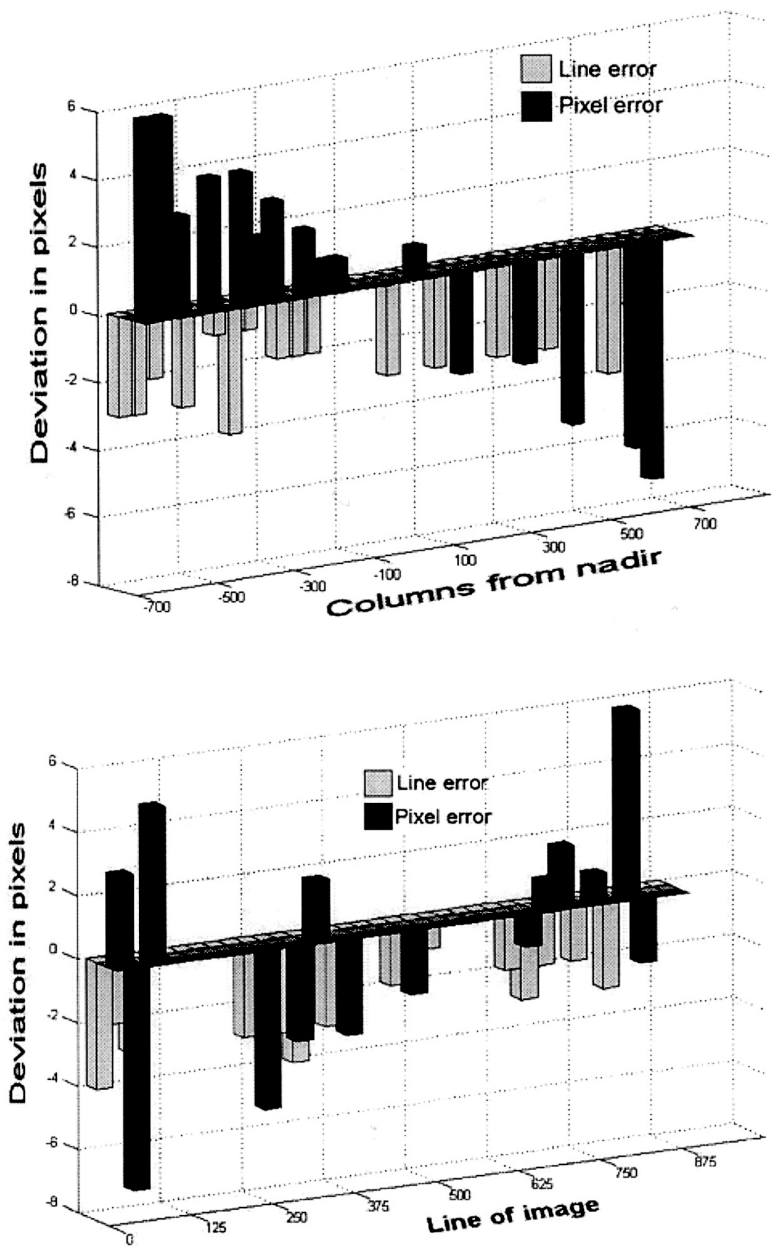

FIG. 1. - Errors between the measured coordinates in the digitised coastline and those calculated by mean of the orbital model for a set of GCPs. (a) As a function of the columns, and (b) as a function of the lines.

lation due to the nominal value of $\lambda_{E}$. The errors in the rows are only of around 3 pixels, basically due to the variation generated by the satellite clock drift and the nominal value of the satellite inclination.

The most important misalignment is generated by the errors in the satellite altitude, which is unavoidable when using a circular orbit. As can be appreciated, the error increases when we move to the edges of the swath. If the nominal satellite altitude estimated is higher or lower than the actual for the orbit under consideration, the error will be positive to the east or west respectively. Finally, the errors do not depend on the line number as can be observed in Figure 1(b).

\section{Automatic procedure of georeferencing}

We have developed an algorithm that allows the elimination of the errors analysed in the previous 
section. This procedure for the automatic NOAAAVHRR images georeferencing shows four clearly separated steps:

1. The image or subscene georeferencing is performed by means of the orbital model using as input the nominal kepplerian elements and the nodal parameters from NOAA.

2. A similarity algorithm is used which identifies automatically coastal features in the coastline-digitised map and in the georeferenced image, using a window correlation of 11 pixels search radius. The similarity measurement used, unlike Bordes et al. (1992), is the cross correlation coefficient,

$$
C_{i, j}=\frac{\sum_{m=1}^{N_{f r}} \sum_{n=1}^{N_{c r}}\left(R_{m, n}-\mu_{R}\right)\left(G_{i+m, j+n}-\mu_{G}\right)}{\left[\sum_{m=1}^{N_{f r}} \sum_{n=1}^{N_{c r}}\left(R_{m, n}-\mu_{R}\right)\right]^{1 / 2}\left[\sum_{m=1}^{N_{f r}} \sum_{n=1}^{N_{c r}}\left(G_{i+m, j+n}-\mu_{G}\right)\right]^{1 / 2}}
$$

where $i$ is the shift in rows, $j$ the shift in columns, $\mathrm{R}$ and $\mathrm{G}$ are the reference and gradient windows and $\mu_{R}, \mu_{G}$ are the means inside the considered windows. This coefficient is a good indicator of the two windows spatial registration.

3 . The values obtained, after passing the different local and global consistency tests, are used for a bilinear regression analysis similar to the usual GCP method,

$$
\begin{aligned}
& \text { Lin' }=a_{o}+a_{1} \cdot \operatorname{Lin}+a_{2} \cdot \text { Col } \\
& \text { Col' }=b_{o}+b_{1} \cdot \operatorname{Lin}+b_{2} \cdot \text { Col }
\end{aligned}
$$

4. Given known mapping functions the georeferenced image, obtained by the orbital model, is transformed and resampled using a zero order interpolation technique.

The global scheme of the procedure is shown in Figures 2. Figure 3 shows the result of the global

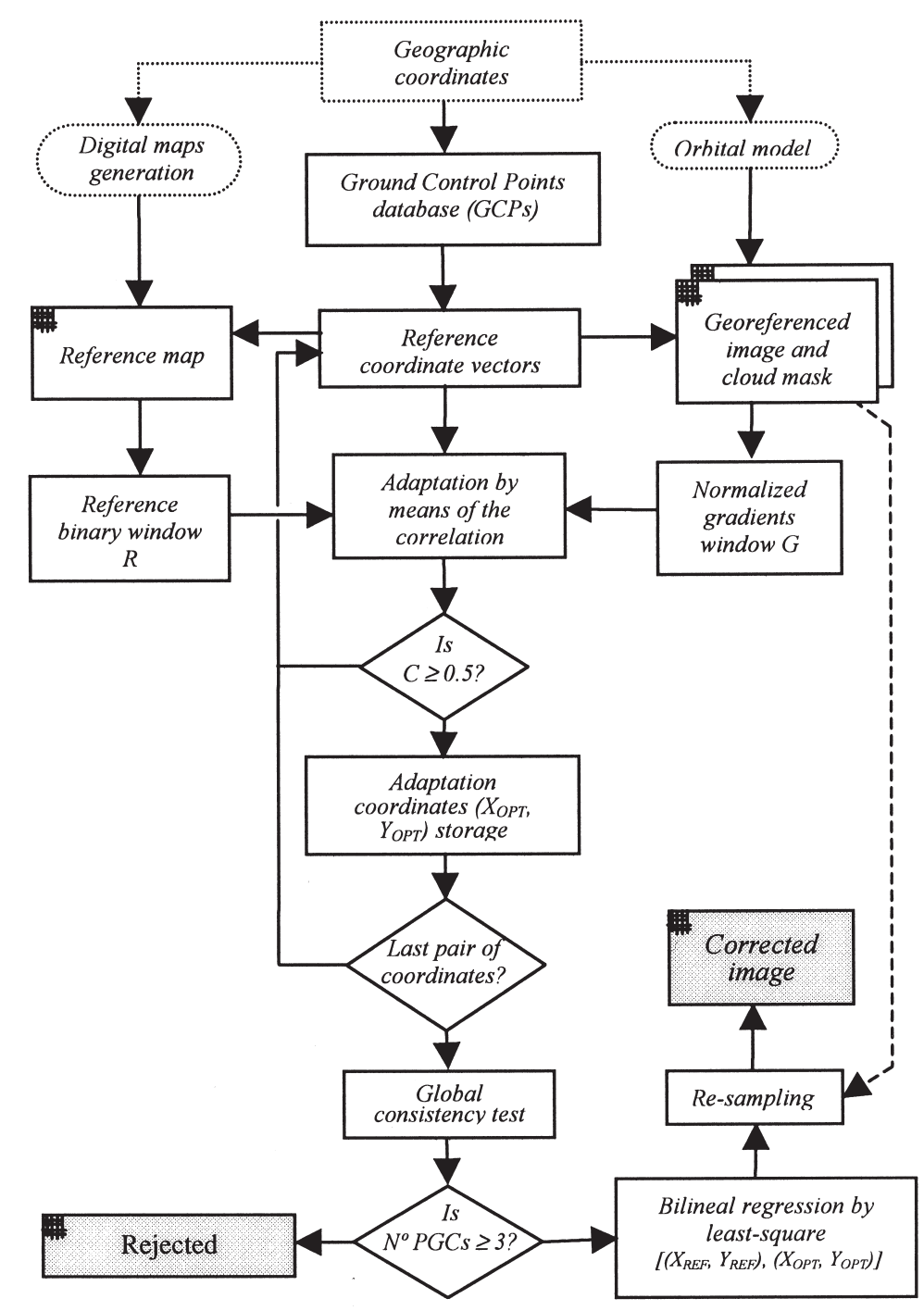

FIG. 2. - Global procedure for the automatic georeferencing of NOAA-AVHRR images. 


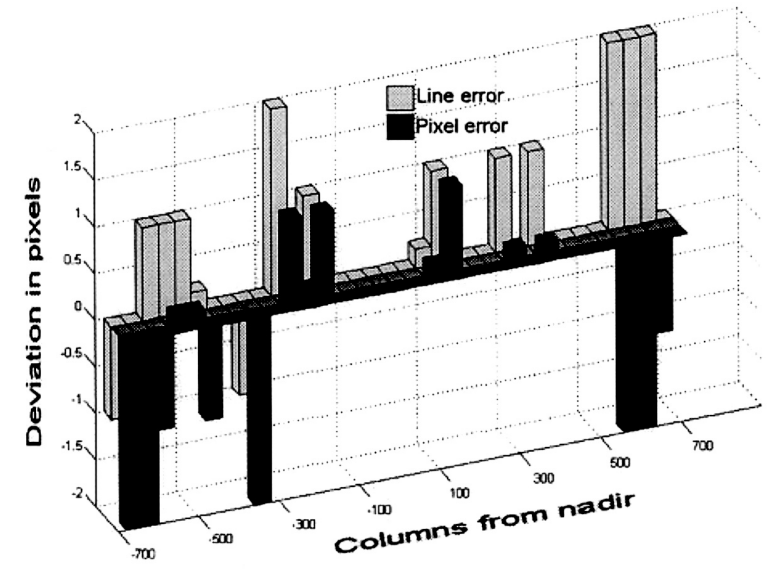

FIG. 3. - Errors between the measured coordinates and those calculated by mean of the orbital model after the correction of the linear and non-linear distortion using the similarity detection algorithm. method applied to the same image (5 June 1998), where it can be seen that this automatic procedure provides similar accuracies to other methods that require manual identification of GCPs.

A set of six representative images was rectified and registered to UTM grid, representing ascending and descending paths as well as different nadir positions. For every image, several GCPs were used for test accuracy. The results are listed in Table 1. Figure 4 illustrates an example of our georeferencing procedure applied to the 5 June 1998 image.

\section{ATMOSPHERIC CORRECTION}

To obtain SST from the brightness temperature of the different channels, several multi-band meth-

TABLE 1. - Results of NOAA-AVHRR image referencing for six test cases. It includes the subscene offset with respect to the satellite nadir, as well as the $n^{\circ}$ of GCPs used in the test. The R.M.S. errors are calculated with the GCPs scaled on coastline digitised and images.

\begin{tabular}{|c|c|c|c|c|c|}
\hline \multirow[t]{2}{*}{ Image } & \multirow[t]{2}{*}{ Trajectory } & \multirow[t]{2}{*}{ Offset Nadir } & \multirow[t]{2}{*}{$\mathrm{N}^{\circ}$ GCPs test } & \multicolumn{2}{|c|}{ Root Mean Square Error } \\
\hline & & & & Line & Pixel \\
\hline 30 September 1997 & $\mathrm{~N} / \mathrm{S}$ & 21.74 & 18 & 1.35 & 1.45 \\
\hline 1 October 1997 & $\mathrm{~S} / \mathrm{N}$ & 6.55 & 16 & 0.95 & 0.89 \\
\hline 5 June 1998 & $\mathrm{~N} / \mathrm{S}$ & -24.88 & 21 & 1.23 & 1.36 \\
\hline 18 January 1998 & $\mathrm{~S} / \mathrm{N}$ & 12.38 & 21 & 1.67 & 1.46 \\
\hline 3 January 1999 & $\mathrm{~N} / \mathrm{S}$ & -22.28 & 15 & 1.17 & 1.2 \\
\hline \multirow[t]{2}{*}{14 June 1999} & $\mathrm{~S} / \mathrm{N}$ & -49.18 & 15 & 1.5 & 1.83 \\
\hline & & & R.M.S. Error Average & 1.31 & 1.365 \\
\hline
\end{tabular}

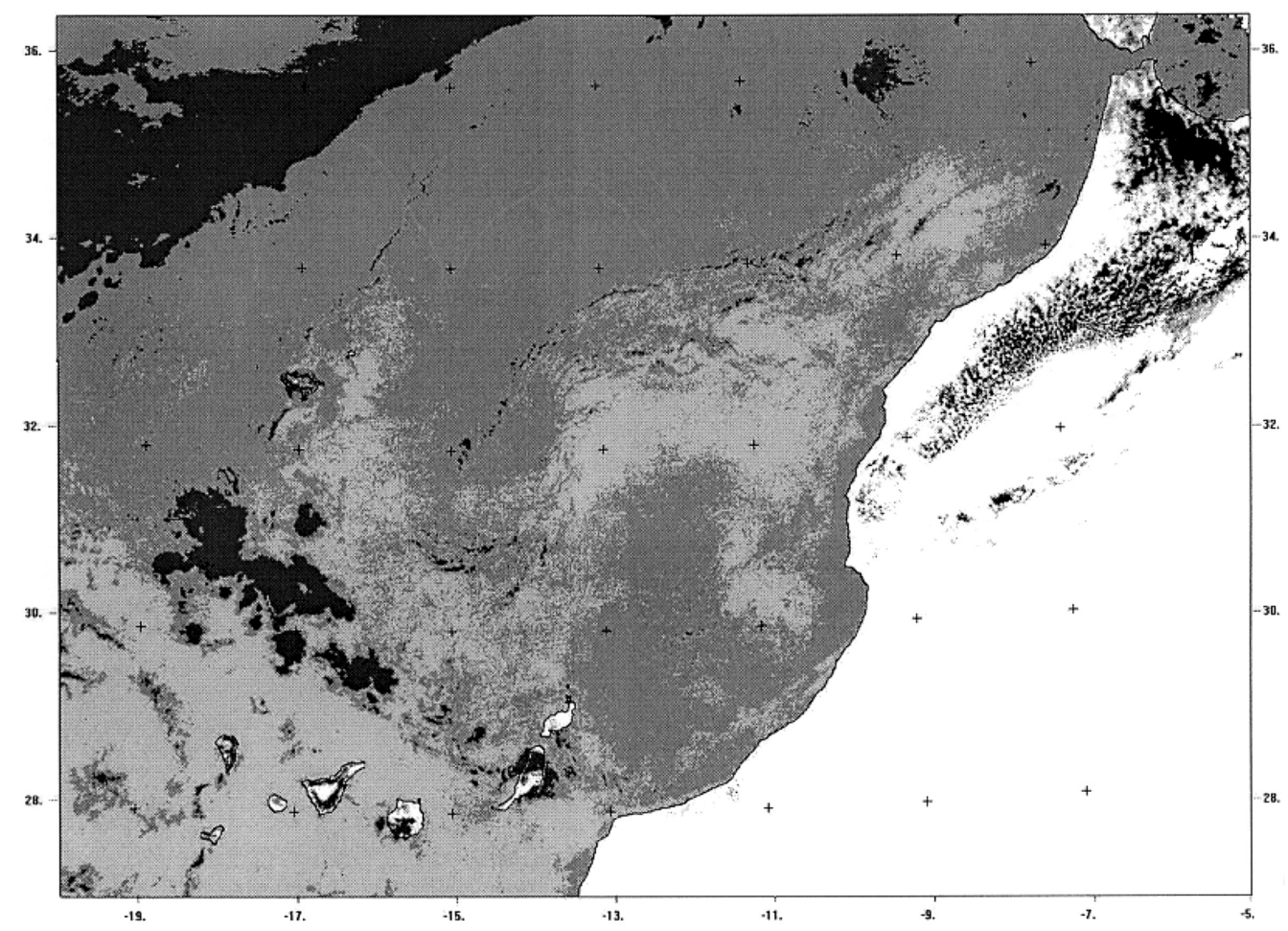

FIG. 4. - NOAA-14/AVHRR image of 5 June 1998 of the Canigo area geometrically corrected into the UTM map projection. The digitized coastline superimposed, obtained from World Data Base II, is for comparison purposes. 
ods have been developed. They are named Multiple Window Method (MWM), that use different bands to calculate the SST (Anding and Kauth, 1970; Prabhakara et al., 1974; McMillin, 1975). For temperature determination, the AVHRR is equipped with three spectral bands: channel $3(3.5-3.9 \mu \mathrm{m})$, channel 4 (10.5-11.5 $\mu \mathrm{m})$ and channel 5 (11.5-12.5 $\mu \mathrm{m})$. The ideal approach (McClain et al., 1985) would use a night-time algorithm giving SST as a function of the three radiative temperatures: SST= f $\left(\mathrm{T}_{3.7}, \mathrm{~T}_{11}, \mathrm{~T}_{12}\right)$, named multiple-window technique, and a day-time algorithm where $\mathrm{SST}=\mathrm{f}\left(\mathrm{T}_{11}\right.$, $\mathrm{T}_{12}$ ), named split-window technique (SWT), where $\mathrm{T}_{3.7}, \mathrm{~T}_{11}$ and $\mathrm{T}_{12}$ are the radiative temperatures at $3.7,11$ and $12 \mu \mathrm{m}$ respectively. Channel 3 is usually very noisy, so at the present time the SWT is commonly used.

There are two kind of approaches to obtain the SWFs. The first one is theoretical, such that the coefficients are calculated from a thermal radiation transmission model using atmospheric profiles that can be observed by radiosonde or specified as standard profiles. The error correction in this approach is directly related with the atmospheric effects. The second is an experimental approach where the coefficients are calculated by the regression analysis between in situ SST measurements and nearly-coincident satellite observations (McMillin and Crosby, 1984). This last approximation, using matchups, is the one that has been used to derive the SWF.

\section{Setting up of the Matchups}

\section{The Research Vessel Data}

Sea Surface Temperature measurements have been obtained during the time periods comprised between December 1996 and December 1998. As shown in Figure 5, the measurements have been performed in the Canigo area $\left(39^{\circ} 15^{\prime} \mathrm{N}-19^{\circ} 15^{\prime} \mathrm{W}\right.$; $\left.26^{\circ} 15^{\prime} \mathrm{N}-6^{\circ} 15^{\prime} \mathrm{W}\right)$. The purpose of the cruises was the study of the seasonal variation of the Canary current in the frame of the Canigo project. Cruises were undertaken every three months between Gran Canaria-Cadiz and Lisboa-Madeira-Canary Islands.

Ship measured temperature was obtained every 10 miles by XBT, CTD and thermosalinograph which logged the temperature at a nominal depth of $2.5 \mathrm{~m}$. The use of thermosalinograph data is not ideal for testing SST retrieval algorithms, so we have not taken it into account. The accuracy of the temperature measurement is around $0.01^{\circ} \mathrm{C}$ for the

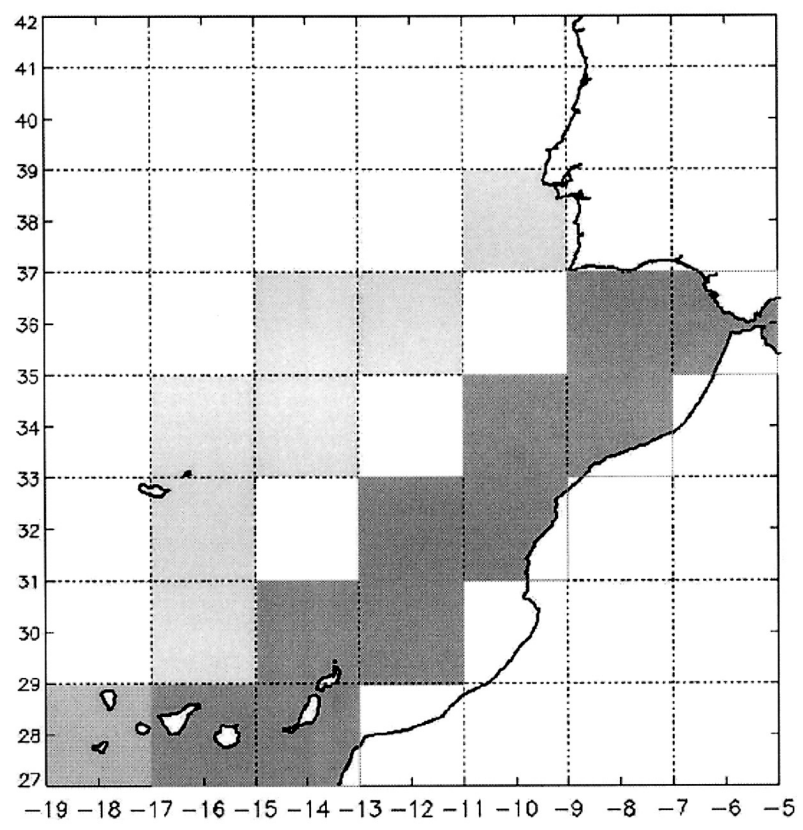

FIG. 5. - Canigo area showing the different cruise track (shady) per formed between December 96-December 98.

XBT and $0.001^{\circ} \mathrm{C}$ for the CTD. In each location, the co-ordinates from a GPS receiver were automatically logged. The total number of existing SST measurements during the period 1996-98 was approximately 250 .

\section{The Satellite Data}

The AVHRR raw data on NOAA-14 is daily received at our station at the Remote Sensing Centre, University of Las Palmas. Figure 6 shows the systematic procedure performed to the images to obtain the matchup database between the in-situ SST measurements and the nearly-coincident satellite observations.

With the objective to obtain very high quality data to estimate the atmospheric model coefficients, the following procedure was followed:

1. Radiometric calibration of the 5 AVHRR sensor channels. Channels 1 and 2 using a linear correction in accordance with the NOAA and channels 3,4 and 5 by means of a non-linear calibration, as described before.

2. Visual inspection of the images: the selected images matching in time with the in-situ measurements were carefully analysed by expert oceanographers by means of a high resolution monitor on its different channels with the objective to disregard those images whose areas closer to the co-ordinates of the in-situ measurements showed: 


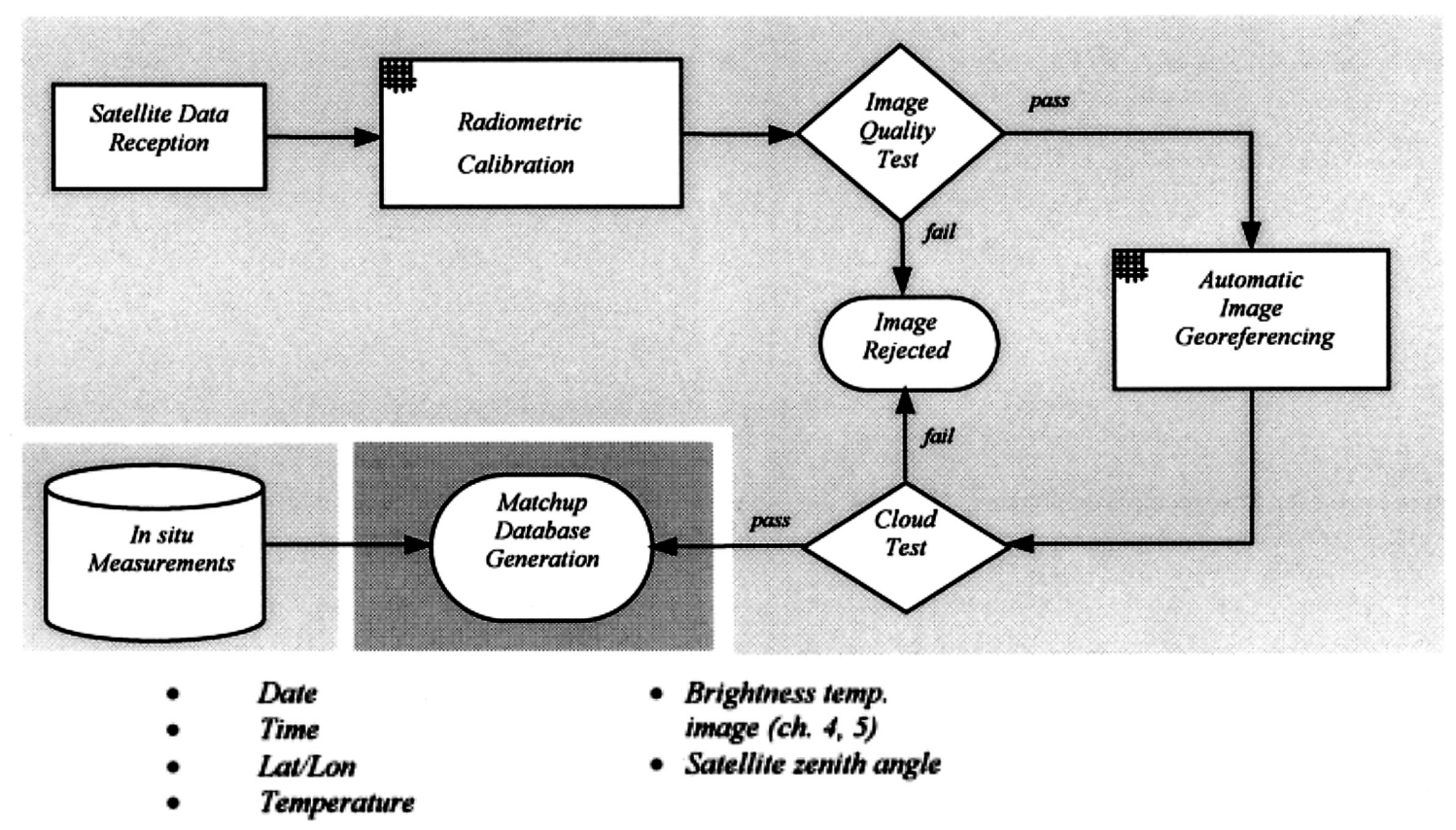

FIG. 6. - Systematic procedure to generate the matchup data set.

- Cloud contamination.

- SST artefacts, such as warm patches (due to diurnal heating) or sand clouds.

3. Images were geometrically corrected according to the orbital method and using a similarity detection algorithm, as described in last section. In order to achieve sub-pixel precision, the sub-scenes were automatically corrected using ground control points located strategically closer to the in-situ measurement co-ordinates.

4. Cloud detection: the algorithm developed is a mutiband threshold method based on the multitest system implemented by Saunders and Kriebel (1988). The method was adapted to our system including some modifications for the Canigo geographical zone based on experimental data. The flow diagrams of the day and night cloud detection algorithms are presented in Figure 7 and will be briefly described next.

Night.- The 3 night tests included in the algorithm are very simple due to the use of fixed thresholds.

- $\mathrm{T}_{11 \mathrm{um}}-\mathrm{T}_{3.7 \mathrm{~m}}$ test: is very useful to detect clouds of low and medium altitude, based on the spectral emissivity variation in the water clouds. Here we make a distinction between the water clouds and the ice particle clouds because they have different physical properties. In our case the threshold has been fixed to $T_{11 \mu m}-T_{3.7 \mu m} \geq 5^{\circ} \mathrm{K}$ to consider cloud presence. An additional test is included to detect clouds in desert areas: $T_{11 \mu \mathrm{m}}-T_{12 \mu \mathrm{m}} \geq 0.2^{\circ} \mathrm{K}$
$-\mathrm{T}_{3.7 \mu \mathrm{m}}-\mathrm{T}_{12 \mu \mathrm{m}}$ test: this night test tries to detect semitransparent clouds composed of ice particles (cirrus). The threshold decided is $T_{3.7 \mu m}-T_{12 \mu m} \geq 3^{\circ} \mathrm{K}$ to consider cloud presence.

- Gross cloud test: the key point is in the definition of the appropriate threshold temperature. Over the sea it is relatively straightforward as the SST varies slowly in space and time. Over land, however, the large day-to-day and area-to-area variability in surface temperatures due to the different land uses and meteorological conditions makes the definition of a single overall discrimination threshold temperature much more difficult. In order to consider cloud presence the following test has been used:

$$
\left(T_{11 \mu m} \leq 283^{\circ} \mathrm{K}\right) \text { and }\left(T_{11 \mu \mathrm{m}}-T_{12 \mu \mathrm{m}}\right) \geq 6^{\circ} \mathrm{K}
$$

Day.- The 3 day tests included in the algorithm are:

- Sunglint test: the sunglint effect generates a considerable increase in the channel $3\left(\mathrm{~T}_{3.7 \mathrm{~m}}\right)$ detected radiance. So, if the temperature difference between channels 3 and 4 is very high, we can assume that is due to the sunglint. The established threshold is $T_{3.7 \mu m}-T_{11 \mu m}>25^{\circ} \mathrm{K}$.

$-\mathrm{R}_{0.9}$ : this test is applied in day images, after the previous ones. In channel 2 , centred at $0.9 \mu \mathrm{m}$, the sea reflectivity has a value of less than $6 \%$, while for clouds is much higher. In our algorithm the visible threshold depends on the solar zenith angle and the difference $T_{3.7 \mu \mathrm{m}}-T_{11 \mu \mathrm{m}}$. 

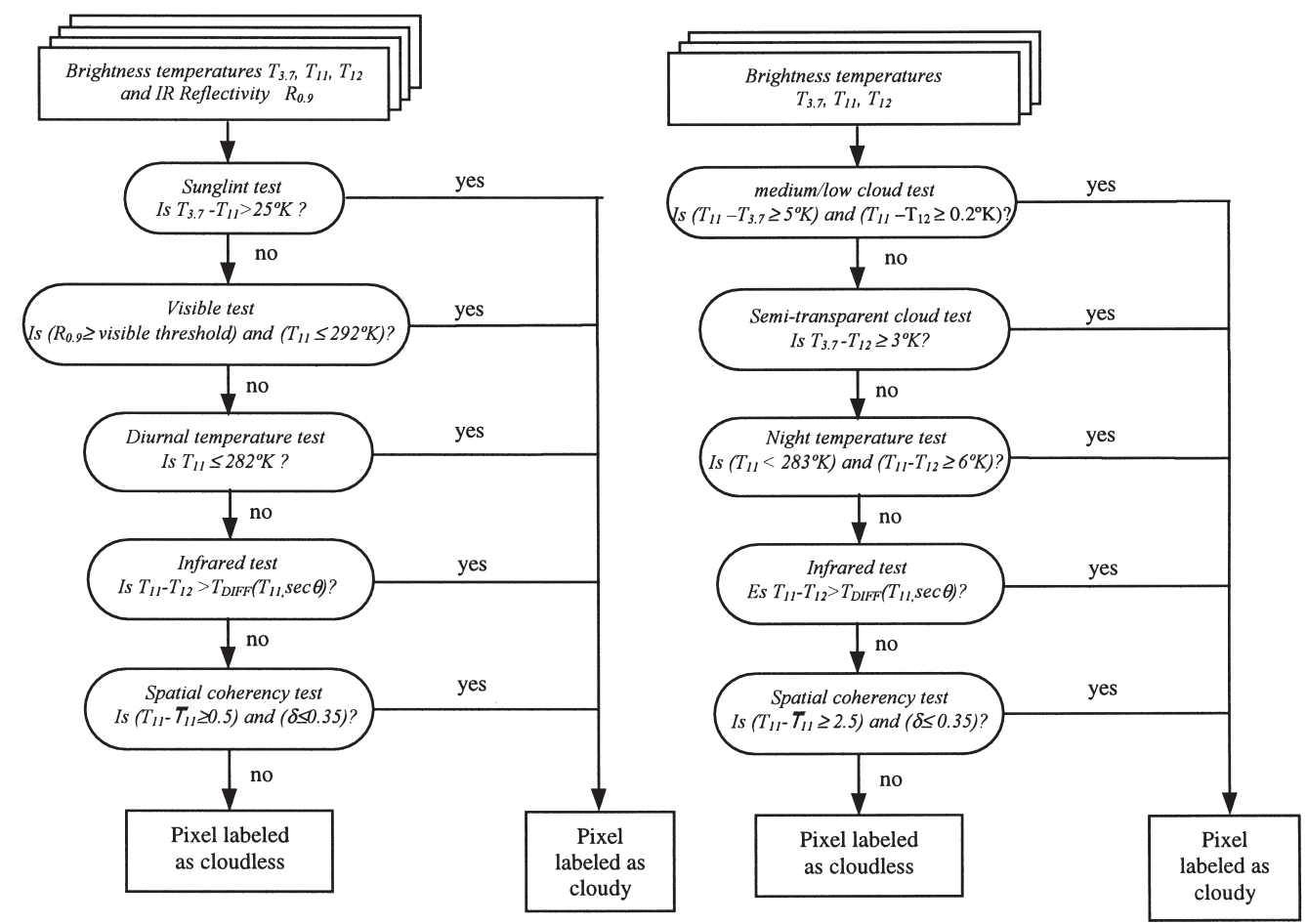

FIG. 7. - Flow diagrams for cloud detection algorithm.

- Gross cloud test: it is a simple thermal infrared threshold test using the brightness temperature calculated from channel 4 . In our case the threshold has been fixed to $T_{11 \mu m} \leq 283^{\circ} \mathrm{K}$ to consider cloud presence.

Common.- The 2 common tests included in the algorithm are:

- $\mathrm{T}_{11 \mu \mathrm{m}}-\mathrm{T}_{12 \mu \mathrm{m}}$ test: this test is used to detect cirrus, whose difference between the thermal IR channels is high. Saunders and Kriebel (1988) proposed a threshold table depending of the channel 4 brightness temperature and the solar zenith angle $\theta$. We proposed an amendment of such table providing corrected thresholds for the Canigo area.

- Space coherence test: the objective is to detect cloud shapes, cirrocumulus, small cumulus and isolated clouds. Saunders and Kriebel (1988) calculated the difference between the channel 4 brightness temperature and the average temperature from the 4 closer pixels, detecting clouds over the sea. We have performed modifications that also allow the detection of cloudy pixels over land. These modifications consist of determining the average temperature and the standard deviation of the 8 neighbouring pixels as,

$$
\bar{T}_{11}=\frac{1}{8}\left(\sum_{i=-1}^{1} \sum_{j=-1}^{1} T_{11}(i, j)\right)
$$

$$
\delta=\sqrt{\frac{1}{8}\left(\sum_{i=-1}^{1} \sum_{j=-1}^{1}\left(T_{11}(i, j)-\bar{T}_{11}\right)^{2}\right)}
$$

establishing the following modified spatial coherency test,

$$
\left(\mathrm{T}_{11}-\mathrm{T}_{11} \geq \mathrm{m}_{\mathrm{thr}}\right) \text { y }\left(\delta \leq \delta_{\mathrm{thr}}\right) \Rightarrow \text { Cloud }
$$

The thresholds $\left(\mathrm{m}_{\mathrm{thr}} \delta_{\mathrm{thr}}\right)$ have been obtained from several experimental checks and will be different for day and night images.

\section{The compilation of comparison data sets}

To generate the match-up database we follow a similar procedure as the one used by Yokoyama and Tanba (1991). In the quantitative test we calculate the standard deviation of the brightness temperatures in a window of $3 \times 3$ pixels centred in each position of the in-situ measurement, for the value of the channels, inside an area of $5 \times 5$ pixels. Unlike the threshold proposed by Yokoyama and Tanba (1991), if the standard deviation was less than $0.12^{\circ} \mathrm{C}$, that is the sensor temperature resolution, we choose the average values of channels 4 and 5 within the window as the corresponding brightness temperature of the in-situ measurement. If it was exceeded we analysed the other 8 windows of $3 \times 3$ inside the searching area of $5 \times 5$ pixels input in the $T_{\text {situ }}$. That window having the minimum standard deviation not 
exceeding $0.12^{\circ} \mathrm{C}$ was used to get the $T_{11}$ and $T_{12}$ respectively.

Finally we apply space-time restrictions: satellite and in-situ observations are considered coincident if they occur within \pm 30 minutes for day images and \pm 1 hour for night images. The identification errors were evaluated within one resolution pixel, which is $1.1 \times 1.1 \mathrm{Km}$ at nadir. We also restricted in-situ measurements to be within about $50^{\circ}$ of the satellite zenith angle. A total of 60 in-situ measurements passed the previous criteria.

\section{SST Algorithms}

Firstly, the algorithms developed by McMillin and Crosby (1984) and Castagné et al. (1986) have been analysed with the intention to improve them. The first is a global algorithm based on the regression of 293 match-ups in $20-70^{\circ} \mathrm{N}$. In the second case the regression coefficients were obtained after adjusting with in-situ measurements with time difference of less than one hour with the satellite pass in the Atlantic Ocean $\left(35-53^{\circ} \mathrm{N}, 1-21^{\circ} \mathrm{W}\right)$, north of our area of interest. Its statistical errors, $R M S D, \mu$ (bias), $\sigma$ (scatter) are presented in Table 2 and Fig.8.

In order to get an algorithm in the Canigo area, we have examined the formal dependencies of the variables $T_{11}$ and $T_{12}$. In both algorithms the $T_{11}$ coefficient is equal to 1 , inducing a bias related to the increment of the atmospheric correction when the SST increases and was initially detected comparing the satellite temperatures and the real measurements with buoys (McClain et al., 1985). Also Barton (1995) points out that regional algorithms trend to have a coefficient close to 1 for $T_{11}$. McMillin et al. (1984), Coll et al. (1994) and Fran atmospheric correction should be provided in terms of a second order polinomy in $T_{11}-T_{12}$. Barton (1995) mentioned the improvements in the split-window

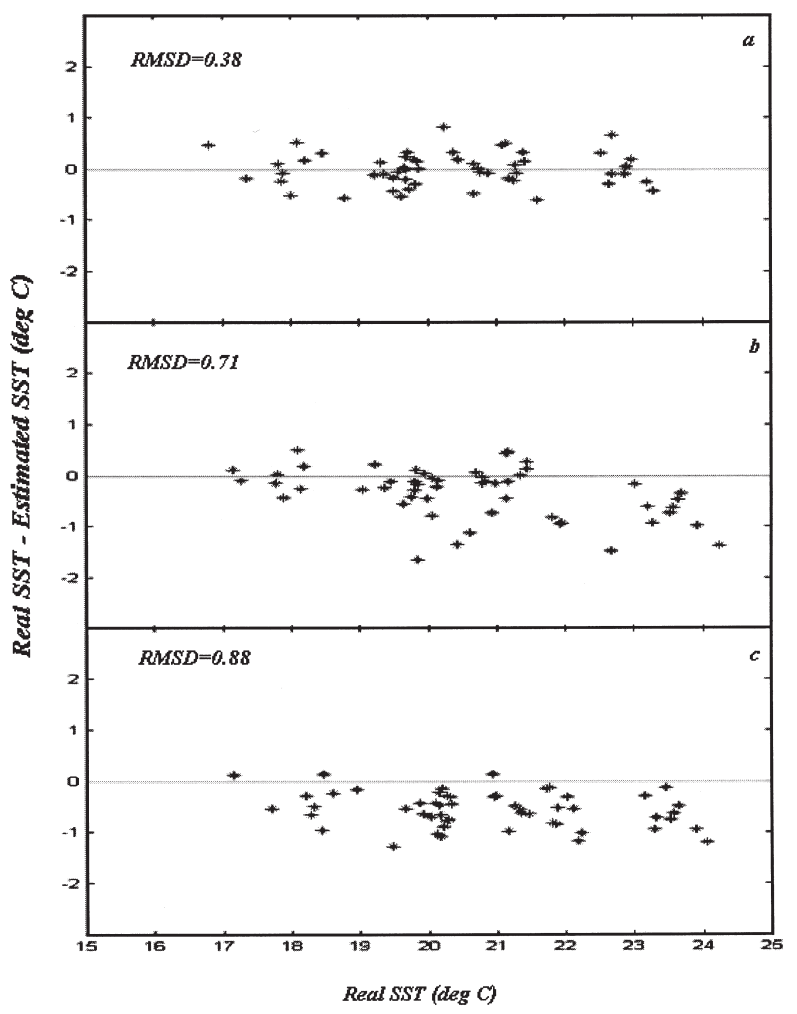

FIG. 8. - Scatter diagrams of the results in the accuracy test for split window function used in the analysis and the SST estimation function derived by the regression analysis.(a) Comparison between the real SST and the estimated by our algorithm. (b, c) Comparison between the real SST and the estimated by the McMillin and Cros by (1984) and Castagné et al. (1986) algorithms, respectively.

algorithm. For our data set we have plotted $T_{\text {situ }}-T_{11}$ versus $T_{11}-T_{12}$, appearing that a quadratic regression seems to be more appropriate than a linear one, especially for higher values of $T_{11}-T_{12}$.

Our algorithm includes the mentioned ideas and it has the following expression:

$S S T=0.9516 T_{11}+\left[2.8122-0.3792\left(T_{11}-T_{12}\right)\right]\left(T_{11}-T_{12}\right)+0.4551$

The results are presented in Figure 8 and Table 2. The average errors are obviously, about the data to obtain the algorithm, $0^{\circ} \mathrm{C}$ and the dispersion is only

TABLE 2. - List of the split window function used in the analysis and the SST estimation function derived by the regression analysis. Statistics of residues by using the Canigo matchup data set.

\begin{tabular}{|c|c|c|c|c|}
\hline SST Estimation Functions & Fundamental data for SWF derivation & Bias & $\sigma(\mathrm{std})$ & RMSD \\
\hline $\begin{array}{l}\text { Castagnè et al. }(1986): \\
\mathrm{SST}=\mathrm{T}_{11}+2 \cdot\left(\mathrm{T}_{11}-\mathrm{T}_{12}\right)+0.5\end{array}$ & $\begin{array}{l}\text { In situ ships SSTs in } \\
35-53^{\circ} \mathrm{N}, 1-21^{\circ} \mathrm{W}\end{array}$ & -0.5560 & 0.6708 & 0.8712 \\
\hline $\begin{array}{l}\text { McMillin and Crosby }(1984): \\
\mathrm{SST}=\mathrm{T}_{11}+2.702 \cdot\left(\mathrm{T}_{11}-\mathrm{T}_{12}\right)-0.582\end{array}$ & $\begin{array}{l}\text { Regression of } 293 \text { matchups in } \\
20-70^{\circ} \mathrm{N} \text {, and } 278-301^{\circ} \mathrm{K}\end{array}$ & -0.3451 & 0.6192 & 0.7088 \\
\hline $\begin{array}{l}\text { This paper: } \\
\mathrm{SST}=0.9516 \cdot \mathrm{T}_{11}+\left[2.8122-0.3792 \cdot\left(\mathrm{T}_{11}-\mathrm{T}_{12}\right)\right] \cdot\left(\mathrm{T}_{11}-\mathrm{T}_{12}\right)+0.4551\end{array}$ & $\begin{array}{l}\text { Regression of } 60 \text { matchups } \\
\text { in } 20-36^{\circ} \mathrm{N}, 5-19^{\circ} \mathrm{W} \text {. } \\
\text { Satellite zenith angle }<50^{\circ}\end{array}$ & 0.0 & 0.385 & 0.385 \\
\hline
\end{tabular}




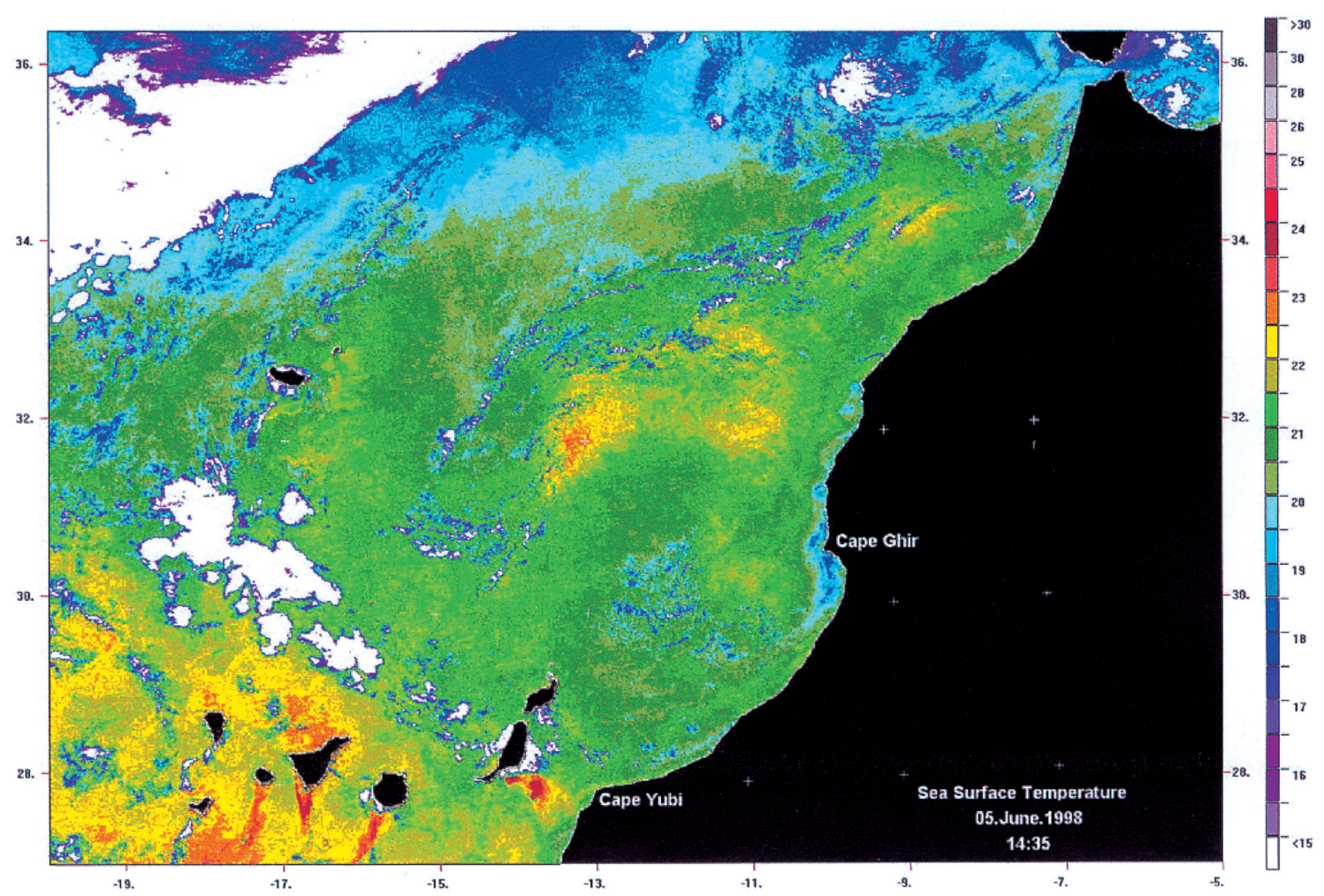

FIG. 9. - Canigo area SST map resulting from equation (6) for the image of 5 June 1998 taken by NOAA-14 (orbit number 17680). Land and clouds are masked in black and white respectively.

of $0.38^{\circ} \mathrm{C}$. Figure 9 shows the SST map obtained applying equation (6) to a NOAA-14 image received by our station.

\section{CONCLUSIONS}

With the procedures developed we have achieved a methodology to obtain automatic SST maps with high accuracy. We have applied to the data a nonlinearity radiance correction procedure and we have also performed the corresponding modifications to the tests proposed by Saunders and Kriebel (1988) in order to detect totally and partially cloudy pixels over sea and land.

We have elaborated a procedure to make the geometric correction of the AVHRR images fully automatic by means of an orbital model and a similarity detection algorithm. The favourable results obtained by this procedure encourage further research, including improvements to overcome the problems related to inaccuracies in orbit modelling, error in timing, and unknown attitude parameters. A great limitation in our similarity detection algorithm is the robustness to partial and global occlusions, a circumstance that is currently under investigation.
We have proposed a split-window equation to perform atmospheric and emissivity correction with a standard error of estimation of only $0.38{ }^{\circ} \mathrm{C}$, restricted to satellite zenith angle less than $50^{\circ}$. The accuracy of the derived SWF was evaluated and compared with other SWFs published. For the future, an algorithm using coefficients depending on the satellite zenith angle should be developed, which takes into account the large zenith variability over a whole AVHRR image. The obtained algorithm should have to be validated with an independent set of data to the one used in the analysis, using, for example, the AVHRR Pathfinder Oceans Matchup Database, that includes a fairly large collection of high-quality in situ SSTs with a reasonably wide distribution in space and time. Also the results obtained would have to be compared with other algorithms that use coefficients dependent on satellite zenith angle.

\section{ACKNOWLEDGEMENTS}

We wish to express our gratitude to the Educational Council of the Canary Islands Government (Contract PI1998/066), and to the CICYT- Commis- 
sion of the European Communities Project (Contract 1FD97-1167) for financial support, and Canigo Project for the in-situ temperature data. We would like to express our special gratitude to $\mathrm{Mr}$ J. Miranda for his help and support. The authors are also thankful to the anonymous referees for their critical review and constructive comments.

\section{REFERENCES}

Anding, D. and R. Kauth. - 1970. Estimation of sea-surface temperature from space. Remote Sensing of Environment, 1: 217-220.

Bachmann M. and J. Bendix. - 1992. An improved algorithm for NOAA-AVHRR image referencing. Int. J. Remote Sensing, 13: 3205-3215.

Barton, I.J. - 1995. Satellite-derived sea surface temperatures: Current status. J. Geoph. Res., 100: 8777-8790.

Bordes, P., P. Brunel and A. Marsouin. - 1992. Automatic Adjustment of AVHRR Navigation. J. Atmospheric and Oceanic Tech., 9: 15-27.

Castagne, N., P. Le Borgne, J. Le Vourch and J.-P. Olry. - 1986. Operational measurements of sea surface temperatures at CMS Lannion from NOAA-7 AVHRR data. Int. J. Remote Sensing, 7: 953-984.

Coll, C., V. Caselles, J.A. Sobrino and E. Valor. - 1994. On the atmospheric dependence of split-window equation for land surface temperature. Int. J. Remote Sensing, 15: 105-122.

Francois C. and C. Ottlé. - 1995. Atmospheric corrections in the thermal infrared: global and water vapour dependent split-window algorithms-applications to ATSR and AVHRR data. IEEE Transactions on Geoscience and Remote Sensing, 34: 457-470.

Ho D., and A. Asem. - 1986. NOAA AVHRR image referencing.
Int. J. Remote Sensing, 7: 895-904.

Illera P., J.A. Delgado and A. Calle - 1996. A navigation algorithm for satellites images. Int. J. Remote Sensing, 17: 577-588.

Krasnopolsky V.M. and D. Breaker. - 1994. The problem of AVHRR image navigation revisited. Int. J. Remote Sensing, 15: 979-1008.

McClain, E.P., W.G. Pichel and C.C. Walton. - 1985. Comparative performance of AVHRR-based multichannel sea surfaces temperatures. J. Geophys. Res., 90: 11587-11601.

McMillin, L.M. - 1975. Estimation of sea surface temperatures from two infrared window measurements with different absorption. J. Geophys. Res., 80: 5113-5117.

McMillin, L.M. and D.S. Crosby. - 1984. Theory and validation of the multiple window sea surface temperature technique. J. Geophys. Res., 89: 3655-3661.

Moreno J.F. and J. Meliá. - 1993. A method for accurate geometric correction of NOAA AVHRR HRPT data, IEEE Transactions on Geoscience and Remote Sensing, 31: 204-226.

Prabhakara, C., G. Dalu and V.G. Kunde. - 1974. Estimation of sea surface temperature from remote sensing in 11 to 13 window region. J. Geophys. Res., 29: 5039-5044.

Rosborough G.W., D.G. Baldwin and W.J. Emery. - 1994. Precise AVHRR image navigation. IEEE Transactions on Geoscience and Remote Sensing, 32: 644-657.

Saunders, P.W. and K.T. Kriebel. - 1988. An improved method for detecting clear sky radiances from AVHRR data. Int. J. Remote Sensing, 9: 123-150.

Steyn-Ross, D.A. and M.L. Steyn-Ross. - 1992. Radiance calibrations for advanced very high resolution radiometer infrared channels. J. Geophys. Res., 97: 5551-5568.

Walton C.C., J.T. Sullivan, C.R.N. Rao and M.P. Weinreb. - 1998. Corrections for detector nonlinearities and calibration inconsistencies of the infrared channels of the advanced very high resolution radiometer infrared channels. J. Geophys. Res., 103: 3323-3337.

Yokoyama R. and S. Tanba. - 1991. Estimation of sea surface temperature via AVHRR of NOAA-9, comparison with fixed buoy data. Int. J. Remote Sensing, 12: 2513-2528. 
